\title{
Hirayama's Disease in a Young Male: A Rare Case Report
}

Mukesh Kumar $^{1}$, Pal Satyajit Singh Athwal ${ }^{2}$, Sandeep Rhandhawa ${ }^{3}$, Sukhmanii Kahlon ${ }^{4}$, Jeevan Shiv Kumar $^{5}$

1. Neurology, Shaheed Mohtarma Benazir Bhutto Medical University, Larkana, PAK 2. Internal Medicine, Saraswathi Institute of Medical Sciences, Hapur, IND 3. Internal Medicine, University of Hawaii, Hawaii, USA 4. Internal Medicine, Medical University of the Americas, Camps, KNA 5. Internal Medicine, J.J.M. Medical College, Davanagere, IND

Corresponding author: Pal Satyajit Singh Athwal, satyajitsinghathwal@gmail.com

\section{Abstract}

Hirayama disease is a rare neurological condition also known as monomelic amyotrophy (MMA). It is a type of cervical myelopathy, which involves the anterior horn cells and affects the distal upper extremities. It is self-limited, asymmetrical lower motor weakness of hands and forearms. Young males are more commonly affected. The condition is hypothesized to occur due to an asymmetric compression of the cervical spinal cord by the dural sac, however, the exact mechanism(s) continue to be investigated. We report a case of a 20 -year-old male who presented with complaints of right hand and forearm weakness, who was diagnosed with Hirayama disease and treated.

Categories: Internal Medicine, Neurology

Keywords: hirayama disease, juvenile non-progressive amyotrophy., monomelic amyotrophy

\section{Introduction}

Keizo Hirayama described this condition as juvenile muscular atrophy of unilateral upper extremity in 1959 [1]. While the term "Monomelic Amyotrophy" was introduced in 1984, to introduce more specificity into the characterization of the disease [2]. The first pathological study was not performed until 1989 [3]. As a motor neuron disorder, it leads to atrophy of the involved muscles of the upper extremity due to imbalance between the vertebral column, and spinal canal content growth makes the dural sac thicker, and these changes displace the posterior dural sac anteriorly on neck flexion, resulting in compression. Sensory and autonomic involvement is rare [4]. Atrophy slowly progresses and reaches a plateau typically over the course of several years before stabilizing. It is more prevalent in Asia with a clear male predominance, particularly in the third decade of life [5]. In India, only 279 cases have been reported over a 35-year period [6].

Received 10/29/2019 Review began 11/08/2019 Review ended 11/12/2019 Published 11/19/2019

๑) Copyright 2019 Kumar et al. This is an open access article distributed under the terms of the Creative Commons Attribution License CC-BY 3.0., which permits unrestricted use, distribution, and reproduction in any medium, provided the original author and source are credited.

\section{Case Presentation}

A 20-year-old male presented with complaints of gradual worsening of right hand and forearm weakness over one year duration. He initially noticed difficulty holding objects with his right hand, but this progressed to difficulty with fine motor skills such as buttoning his shirt and writing. He noticed an insidious decrease in muscle mass of the right hand and forearm. The patient denied any loss of sensation, autonomic dysfunction, bowel or bladder changes, or axial neck pain. There was a noncontributory family history, past medical history and past surgical history, and no history of trauma or prior hospitalization. On examination, muscle bulk was reduced in the right forearm and hand as compared to the left as evident from Figure 1 and Figure 2. The interossei, thenar, hypothenar, flexor and extensor muscles were involved, and the brachioradialis was spared. Tone was slightly reduced at the right wrist with muscle strength of 3/5 in the right hand. Deep tendon reflexes were 2+ bilaterally in the upper limbs. Sensation was intact bilaterally. The plantar reflex was normal. Vital signs were within normal limits. 


\section{Cureus}

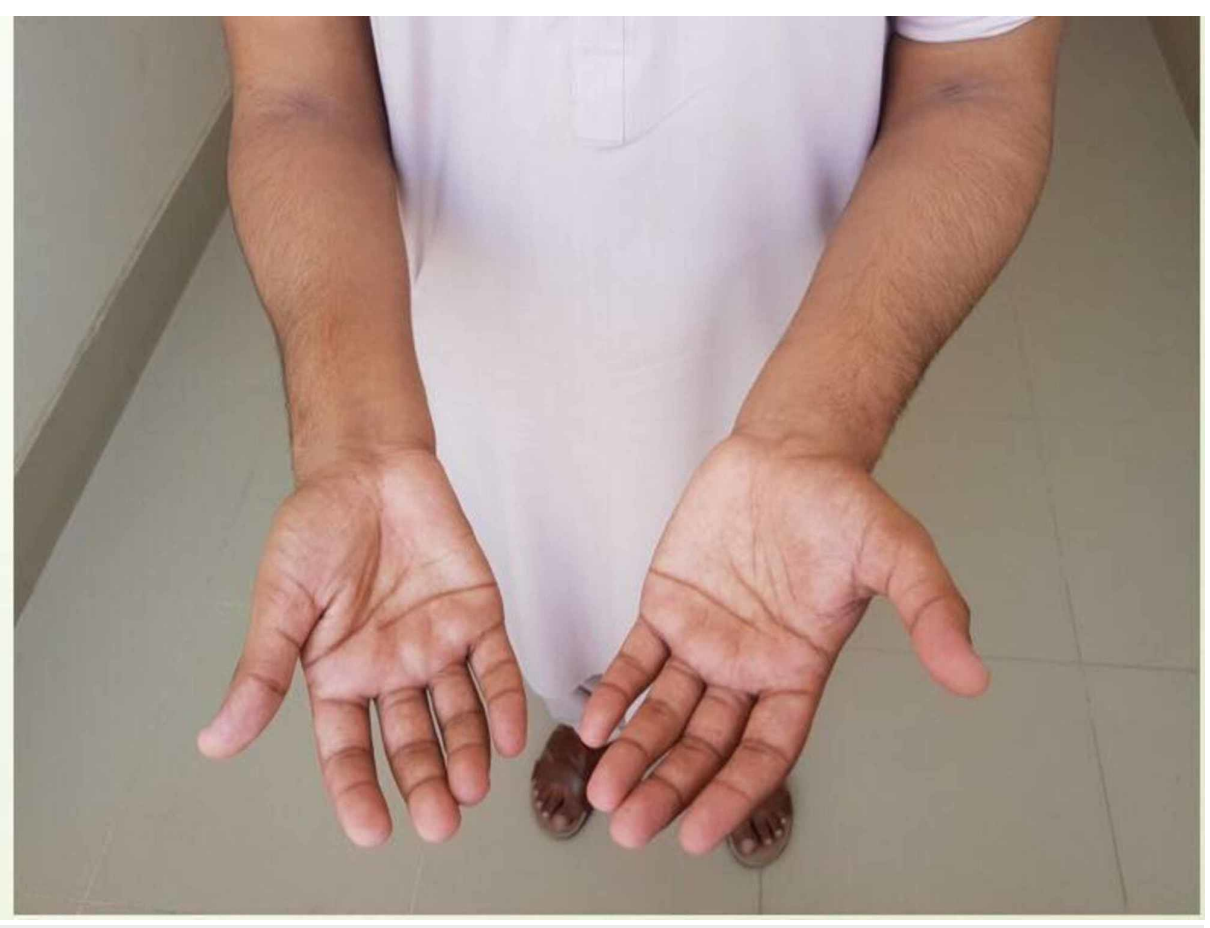

FIGURE 1: Atrophied right forearm compared to left

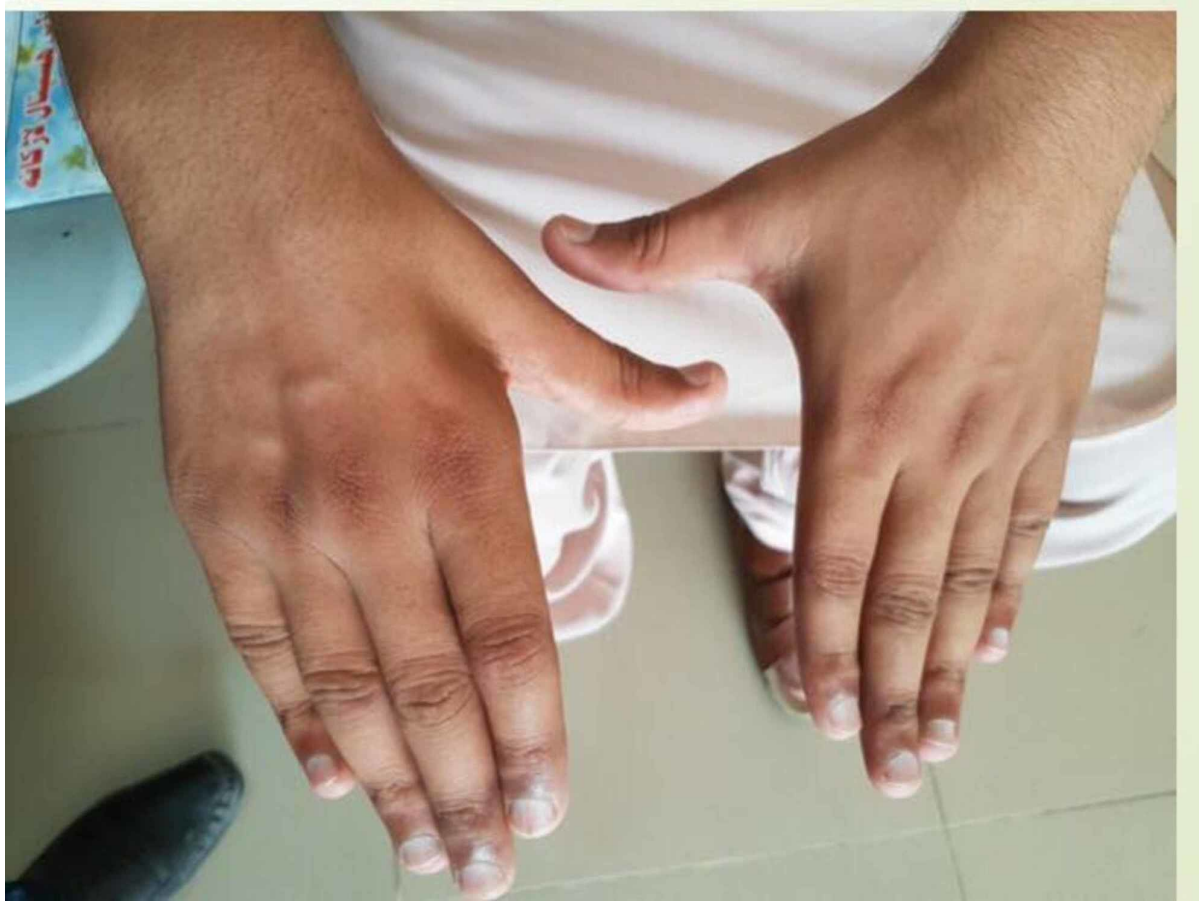

FIGURE 2: Right hand showing muscular atrophy as compared to the left hand

Nerve conduction studies were done with following results:

Motor: Bilateral median and ulnar nerve conduction revealed normal distal latencies, compound motor action potential (CMAP) amplitudes and conduction velocities. The CMAP amplitudes were relatively lower on the right side. The right ulnar short segmental (inching) study over a 10-cm segment across the elbow revealed evidence of focal demyelination (focal slowing) at the elbow crease. 


\section{Cureus}

Sensory: The right median and ulnar nerve conduction studies revealed normal onset latencies, sensory nerve action potentials (SNAP) amplitudes and conduction studies.

EMG/Needle exam: Needle electromyography (EMG) exam revealed evidence of a chronic axonal neurogenic process in bilateral C8-T1 more than C7 innervated musculature, bilaterally along with the mild active denervation in some of the C8-T1 innervated muscles. The process was more severe on the right side.

Magnetic resonance imaging (MRI) showed a loss of cervical lordosis with C5-C6 and C5-C7 thecal sac indentation. X-rays ruled out any osteophytes or bony deformity (Figure 3). The patient's complete blood count, kidney function test, and liver function tests were within normal limits as per the standardized lab values. All viral markers including HIV were negative. Hirayama disease was diagnosed based on the history, muscle involvement, nerve conduction studies and MRI findings. The patient was advised to use cervical collar to prevent neck flexion and further compression of the cervical cord.

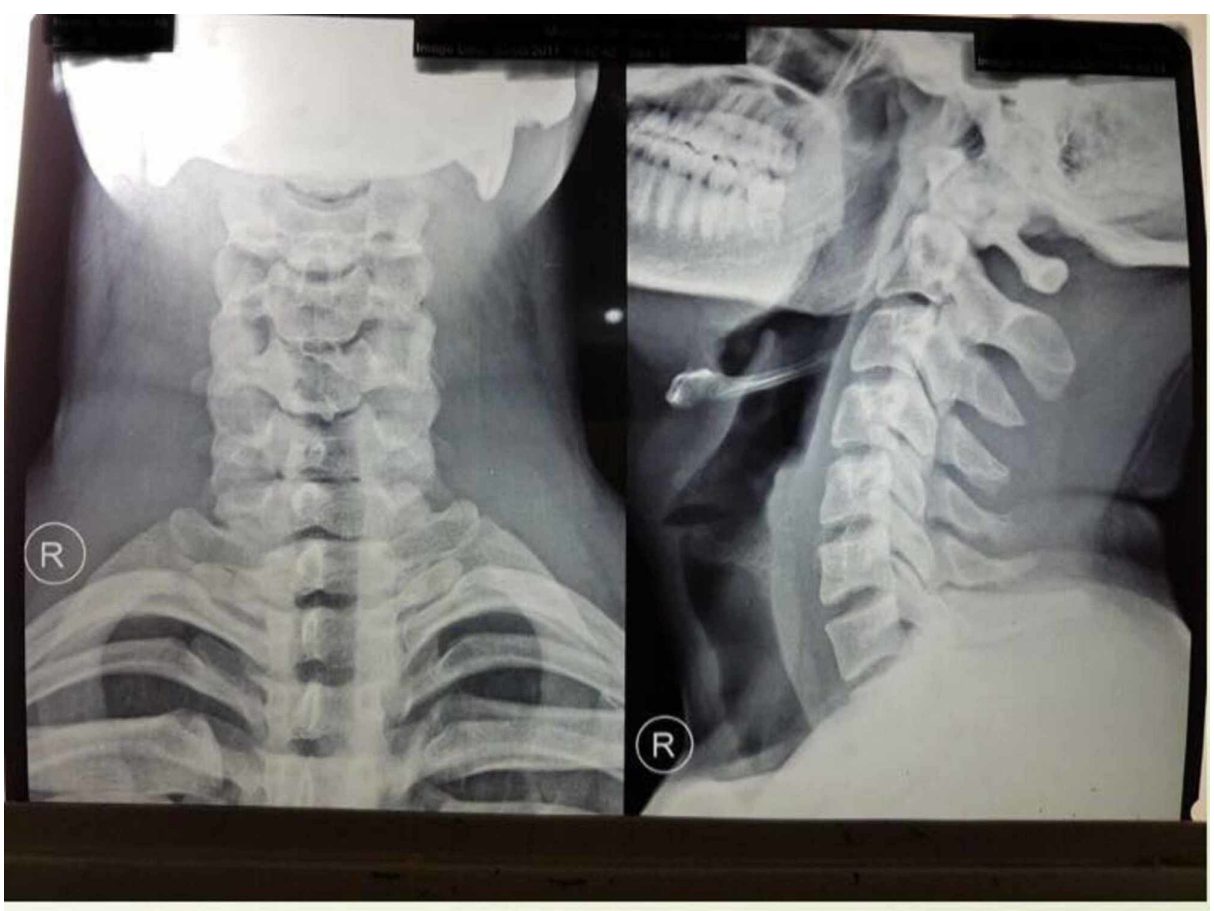

FIGURE 3: X-ray cervical spine of the patient

\section{Discussion}

Monomelic amyotrophy is a rare neurological condition characterized by asymmetrical weakness and wasting of muscles of upper limb, involving predominantly the lower cervical cord C7, C8, and T1 myotomes. Sensory and reflex examination is normal. Autonomic system is involved rarely as reported by Hassan et al. [7]. According to Tashiro et al. [8], the following criteria are important for diagnosis:

(1) Distal predominant muscle weakness and atrophy in the forearm and hand;

(2) Involvement of the unilateral upper extremity in most cases;

(3) Onset between the ages of 10 to early 20s;

(4) Insidious onset with gradual progression for the first several years, followed by stabilization;

(5) No lower extremity involvement;

(6) No sensory disturbance or tendon reflex abnormalities; and

(7) Exclusion of other diseases.

All of these points were fulfilled by our case, which helped make the diagnosis. While pathogenesis remains unknown, it is believed that impaired functioning of anterior horn cells due to pressure atrophy at the level of C5-T1 may play a role [3]. The imbalance between the vertebral column and spinal canal content growth 
makes the dural sac thicker, and these changes displace the posterior dural sac anteriorly on neck flexion, resulting in compression. Repeated compression or prolonged flexion may lead to ischemic injury to anterior horn cells, which are particularly vulnerable. Cervical X-ray usually shows no changes, as it was the case here. MRI on flexion of the neck typically shows anterior displacement of the posterior dural sac along with a crescent mass in the posterior epidural space of the lower cervical canal [9]. A study conducted by Guo et al. on 14 patients with Hirayama disease showed characteristic segmental injury in the anterior horn cells of the lower cervical cord, while a few patients exhibited extensive neurogenic injury [10]. Other conditions, like demyelinating polyneuropathy in HIV, congenital neuropathies, amyotrophic lateral sclerosis, post-polio syndrome, and syringomyelia should be ruled out by history and appropriate clinical investigation. Diagnosis is made based on clinical and diagnostic findings, and MRI and EMG are often necessary tests. Monomelic amyotrophy is a self-limiting condition without definitive treatment. Cervical collars can be used to prevent the neck flexion, compression and mitigate symptom exacerbation. Apart from permanent cervical fixation, posterior cervical decompression with coagulation of epidural venous plexus is a technique that seems to be effective.

\section{Conclusions}

According to our case report, Hirayama's disease is a rare type of monomelic amyotrophy neurological condition, characterized by asymmetrical weakness and wasting of muscles of the upper limb, involving predominantly the lower cervical cord C7, C8, T1 myotomes and sparing the autonomic system. The pathophysiology is due to the displacement of the posterior cervical dural sac, which causes spinal cord compression leading to ischemia of the anterior horn cells. This disproportionate growth of the cervical cord and spine usually is seen in adolescence. This case study may be important because if diagnosed early, its progression can be stopped by simple management using cervical collars and can decrease the long-term surgical interventions.

\section{Additional Information \\ Disclosures}

Human subjects: Consent was obtained by all participants in this study. Conflicts of interest: In compliance with the ICMJE uniform disclosure form, all authors declare the following: Payment/services info: All authors have declared that no financial support was received from any organization for the submitted work. Financial relationships: All authors have declared that they have no financial relationships at present or within the previous three years with any organizations that might have an interest in the submitted work. Other relationships: All authors have declared that there are no other relationships or activities that could appear to have influenced the submitted work.

\section{References}

1. Hirayama K, Toyokura Y, Tsubaki T: Juvenile muscular atrophy of unilateral upper extremity: a new clinical entity. J Psychiatr Neurol. 1959, 61:2190-2197.

2. Gourie-Devi M, Suresh TG, Shankar SK: Monomelic amyotrophy. Arch Neurol. 1984, 41:388-394. 10.1001/archneur.1984.04050160050015

3. Hirayama K, Tomonaga M, Kitano K, Yamada T, Kojima S, Arai K: Focal cervical poliopathy causing juvenile muscular atrophy of distal upper extremity: a pathological study. J Neurol Neurosurg Psychiatry. 1987, 50:285-290. 10.1136/jnnp.50.3.285

4. Yoo SD, Kim HS, Yun DH: Monomelic amyotrophy (Hirayama disease) with upper motor neuron signs: a case report. Ann Rehabil Med. 2015, 39:122-127. 10.5535/arm.2015.39.1.122

5. Pal PK, Atchayaram N, Goel G, Beulah E: Central motor conduction in brachial monomelic amyotrophy. Neurol India. 2008, 56:438-443.

6. Nalini A, Gourie-Devi M, Thennarasu K, Ramalingaiah AH: Monomelic amyotrophy: clinical profile and natural history of 279 cases seen over 35 years (1976-2010). Amyotroph Lateral Scler Frontotemporal Degener. 2014, 15:457-465. 10.3109/21678421.2014.903976

7. Hassan KM, Sahni H, Jha A: Clinical and radiological profile of Hirayama disease: a flexion myelopathy due to tight cervical dural canal amenable to collar therapy. Ann Indian Acad Neurol. 2012, 15:106-112. 10.4103/0972-2327.94993

8. Tashiro K, Kikuchi S, Itoyama Y, et al.: Nationwide survey of juvenile muscular atrophy of distal upper extremity (Hirayama disease) in Japan. Amyotroph Lateral Scler. 2009, 7:38-45. 10.1080/14660820500396877

9. Mukai E, Matsuo T, Muto T, Takahashi A, Sobue I: Magnetic resonance imaging of juvenile-type distal and segmental muscular atrophy of upper extremities. (Article in Japanese). Rinsho Shinkeigaku. 1987, 27:99107.

10. Guo XM, Qin Y, Huang C: Neuroelectrophysiological characteristics of Hirayama disease: report of 14 cases . Chin Med J (Engl). 2012, 125:2440-2443. 10.3760/cma.j.issn.0366-6999.2012.14.008 